\title{
Regio- and Stereospecific Syntheses and Nitric Oxide Donor Properties of $(E)-9$ and $(E)$-10-Nitrooctadec-9-enoic Acids
}

\author{
Michael J. Gorczynski, Jinming Huang, and S. Bruce King \\ Department of Chemistry, Wake Forest University, Winston-Salem, NC 27109 \\ S. Bruce King: kingsb@wfu.edu
}

\begin{abstract}
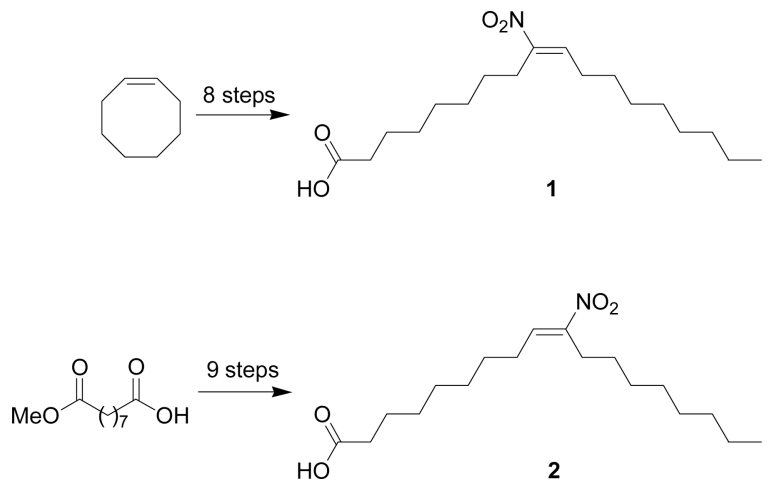

Nitrated fatty acids act as endogenous peroxisome proliferator-activated receptor $\gamma$ (PPAR $\gamma$ ) ligands and nitric oxide (NO) donors. We describe the first specific preparation of the two regioisomers of nitrooleic acid, (E)-9-nitrooctadec-9-enoic acid (1) and (E)-10-nitrooctadec-9enoic acid (2) from cis-cyclooctene and mono-methyl azelate, respectively. These syntheses rely upon a Henry condensation between a nine-carbon nitro component and a nine-carbon aldehyde. Preliminary chemiluminescence NO detection studies reveal the ability of these nitrated fatty acids to release NO.
\end{abstract}

Nitrated fatty acids have emerged as a unique class of endogenously produced signaling molecules. Initial studies reveal that nitrated derivatives of linoleic acid (18:2) occur in concentrations of $\sim 500 \mathrm{nM}$ in human red blood cells and plasma making nitrated fatty acids the single largest pool of bioactive nitrogen oxides in the vasculature. ${ }^{1}$ Additional studies show that nitrolinoleate $\left(\mathrm{LNO}_{2}\right)$ acts as a ligand of the peroxisome proliferator-activated receptor $\gamma(\operatorname{PPAR} \gamma)^{2}$ Activation of this transcription factor results in gene expression that affects numerous critical cellular processes including growth and differentiation, inflammation, metabolic homeostasis and vasomotor processes. ${ }^{3}$ Other studies show that $\mathrm{LNO}_{2}$ also spontaneously releases nitric oxide (NO), an endogenous free radical signaling mediator that regulates a number of biological processes including blood pressure, neurotransmission, and platelet aggregation. ${ }^{4,5}$ These interesting molecules thus bridge fatty acid-derived signaling with nitric oxide-mediated signaling. More recent work shows that (E)-9- and (E)-10-nitrooctadec-9-enoic acids (nitrated oleic acids, $\mathrm{OA}-\mathrm{NO}_{2}$ ) occur with a

Correspondence to: S. Bruce King, kingsb@wfu . edu.

Supporting Information Available: Full experimental details for the preparation of all intermediates and products, as well as complete spectroscopic and analytical data for all characterized compounds. Copies of ${ }^{1} \mathrm{H}$ and ${ }^{13} \mathrm{C}$ NMR spectra for $1,2,4,6,7,12$, and $\mathbf{1 3}$ are also included. This material is available free of charge via the Internet at http://pubs.acs.org. 
higher prevalence in human blood and urine than $\mathrm{LNO}_{2} \cdot{ }^{6}$ Additionally, $\mathrm{OA}-\mathrm{NO}_{2}$ activates PPAR $\gamma$ with a greater potency than $\mathrm{LNO}_{2}{ }^{6}$

Current methods for the synthesis of these nitrated fatty acids involve the modification of previous nitroselenylation strategies used to synthesize conjugated nitroalkenes. ${ }^{7,8}$ Alternatively, addition of nitronium tetrafluoroborate to an unsaturated fatty acid or fatty acid hydroperoxide also forms nitrated fatty acids. ${ }^{9}$ These non-specific procedures form regioisomeric mixtures of nitro alkene products that require multiple purification steps. More importantly, these non-specific syntheses prevent strict analysis of the structural requirements for the biological activity of these unique molecules. Here we report the first regio- and stereospecific syntheses of (E)-9-nitro-octadec-9-enoic acid (1) and (E)-10nitrooctadec-9-enoic acid (2) and show that these nitrated lipids spontaneously release nitric oxide.

Scheme 1 describes the retrosynthetic strategy for preparation of the specific nitrooleic acid regio-isomers. The basic strategy relies upon the nitro aldol condensation (Henry reaction) between a nine-carbon nitro component and nine-carbon aldehyde as the critical carboncarbon bond forming reaction. Elimination of water from the corresponding nitro alcohols followed by hydrolysis would form the nitroalkenes $\mathbf{1}$ and $\mathbf{2}$.

The regio- and stereospecific synthesis of $\mathbf{1}$ (Scheme 2) begins with ozonolysis of ciscyclooctene to form aldehyde $(\mathbf{3})$ as previously reported. ${ }^{10}$ Condensation of $\mathbf{3}$ with nitromethane and a catalytic amount of potassium tert-butoxide ( $t$-BuOK) affords nitro alcohol (4). ${ }^{11}$ Acetylation of $\mathbf{4}$ proceeds smoothly with acetic anhydride using DMAP as a catalyst and reduction of the corresponding nitro acetates with a $1 \mathrm{M}$ solution of sodium borohydride in ethanol gives nitroalkane (5) in $83 \%$ yield for the two steps. ${ }^{11,12}$ Condensation of nitroalkane (5) with nonanal and a catalytic amount of $t$-BuOK gives nitro alcohol (6) as a mixture of diastereomers in high yield. ${ }^{11}$ One-pot acetylation followed by dehydro-acetylation of $\mathbf{6}$ exclusively gives the methyl ester (7) in moderate yield after purification by column chromatography. ${ }^{11}{ }^{1} \mathrm{H}$ NMR chemical shift analysis suggests the exclusive formation of the $E$ isomer as the alkene proton of $E$-nitroalkenes display a characteristic chemical shift of $\sim \delta 7.00 \mathrm{ppm}$ while the alkene proton of $Z$-nitroalkenes has a characteristic chemical shift of approximately $\delta 5.80 \mathrm{ppm} .{ }^{13}$

Hydrolysis of the methyl ester of 7 proved somewhat difficult due to the reactive nature of the nitroalkene. Treatment of 7 with $1 \mathrm{M}$ aq. $\mathrm{NaOH}$ (room temperature to $70{ }^{\circ} \mathrm{C}$ ) fails to transform 7 to 1 as judged by TLC and ${ }^{1} \mathrm{H}$ NMR. Increasing the temperature to $80{ }^{\circ} \mathrm{C}$ or higher resulted in complete decomposition of $\mathbf{7}$ (presumably through retro-Henry reactions) with no evidence of $\mathbf{1}$. Incubation of $\mathbf{7}$ with iodotrimethylsilane (TMSI), made in situ from TMSCl and NaI, in refluxing acetonitrile also results in the complete decomposition of 7 . Ultimately, treatment of 7 with $6 \mathrm{M}$ aq. $\mathrm{HCl}$ at reflux for $12 \mathrm{~h}$ forms $1(\delta 7.08 \mathrm{ppm}$ for nitroalkene proton) in 58\% yield (69\% yield brsm). Both ${ }^{1} \mathrm{H}$ and ${ }^{13} \mathrm{C}$ NMR spectroscopy confirm the presence of a single regioisomer and chemical shift analysis again indicates the formation of the E-stereoiosmer.

The synthesis of $\mathbf{2}$ begins with the borane reduction of commercially available mono-methyl azelate to give alcohol (8) in $89 \%$ yield as previously reported (Scheme 3). ${ }^{14}$ PCC oxidation of 8 in $\mathrm{CH}_{2} \mathrm{Cl}_{2}$ gives aldehyde (9). ${ }^{14}$ Preparation of the nine carbon nitro-containing component begins with the condensation of octanal with nitromethane and a catalytic amound of $t$-BuOK to give nitro alcohol (10). ${ }^{11}$ Acetylation of $\mathbf{1 0}$ followed by reduction with a $1 \mathrm{M}$ solution of sodium borohydride in ethanol affords nitroalkane (11). ${ }^{11,12}$ Condensation of aldehyde (9) and nitroalkane (11) furnishes nitro alcohol (12) as a mixture of diastereomers in $66 \%$ yield. ${ }^{11}$ Acetylation followed by dehydroacetylation of nitro 
alcohol (12) gives $\mathbf{1 3}$ as a single regioisomer ( $\delta 7.06 \mathrm{ppm}$ for the nitroalkene proton). ${ }^{11}$ Hydrolysis of ester $\mathbf{1 3}$ in refluxing $6 \mathrm{~N}$ aq. $\mathrm{HCl}$ for $12 \mathrm{~h}$ yields $2(\delta 7.06 \mathrm{ppm}$ for the nitroalkene proton) in $53 \%$ yield (59\% yield brsm).

Chemiluminescence NO detection experiments provide the first evidence that $(E)$-9- and (E)-10-nitrooctadec-9-enoic acids release NO and nitrite (Table 1). Direct analysis of the reaction headspace shows the time-dependent formation of $\mathrm{NO}$ upon anaerobic incubation of $\mathbf{1}$ and $\mathbf{2}$ in buffer at room temperature. Analysis of the reaction solution following KI/acetic acid reduction reveals the time-dependent release of nitrite from $\mathbf{1}$ and $\mathbf{2}$. At this time, it remains unclear whether nitrite directly forms from the decomposition of $\mathbf{1}$ and $\mathbf{2}$ or from further oxidation of NO. Incubation of the methyl esters ( 7 and 13) under similar conditions followed by chemiluminescence $\mathrm{NO}$ detection also shows the release of $\mathrm{NO}$ and nitrite (Table 1). While these expeirments clearly show the spontaneous release of NO from these compounds, the amount of NO produced is quite low ( $<1 \%$ under these condidtions) indicating the relative stability of these compounds. It remains to be determined whether this amount of NO release from these nitrated lipids directly participates in the observed biological activities of these compounds. These synthetic studies provide material to further examine the role of NO in the action of these lipid derivatives.

Proposed mechanisms that include nitric oxide release from nitro alkenes currently include a modified Nef reaction and a nitro alkene rearrangement to a nitrite ester followed by $\mathrm{N}-\mathrm{O}$ bond homolysis. ${ }^{4}$ Both of these mechanisms yield carbon based radicals as organic products and we have yet to determine the organic products in our decompositions. Neither of these mechanisms explains the observed differences in $\mathrm{NO}$ and nitrite release between the regio isomers $\mathbf{1}$ and $\mathbf{2}$ and $\mathbf{7}$ and $\mathbf{1 3}$ suggesting possible other operative pathways for NO release. The developed synthetic pathways should form the basis of new studies to clearly determine the rate and mechanism of $\mathrm{NO}$ release from these specific compounds and also whether nitroalkenes represent a new general class of $\mathrm{NO}$ or nitrite donors. ${ }^{4}$

In summary, this work describes the first regio- and stereospecific syntheses of (E)-9- and (E)-10-nitrooctadec-9-enoic acids ( $\mathbf{1}$ and $\mathbf{2}$ ), endogenously produced nitrated fatty acids capable of activation of the PPAR $\gamma$ receptor. In addition, these studies reveal the ability of these compounds to act as NO donors, similar to nitrated linoleic acid. These synthetic advances allow a detailed examination of the relationship between the structure and biology of this newly discovered class of cell signaling reagents and such studies are currently underway.

\section{Supplementary Material}

Refer to Web version on PubMed Central for supplementary material.

\section{Acknowledgments}

This work was supported by the National Institutes of Health (HL62198, SBK). The NMR spectrometer used in this work was purchased with partial support from NSF (CHE-9708077) and the North Carolina Biotechnology Center (9703-IDG-1007).

\section{References}

1. (a) Lima ES, Di Mascio P, Rubbo H, Abdalla DSP. Biochemistry. 2002; 41:10717. [PubMed: 12186558] (b) Baker PRS, Schopfer FJ, Sweeney S, Freeman BA. Proc. Natl. Acad. Sci. USA. 2004; 101:11577. [PubMed: 15273286]

2. Schopfer FJ, Lin Y, Baker PRS, Cui T, Garcia-Barrio M, Zhang J, Chen K, Chen YE, Freeman BA. Proc. Natl. Acad. Sci. USA. 2005; 102:2340. [PubMed: 15701701] 
3. (a) Bishop-Bailey D, Wray J. Prostaglandins Other Lipid Mediat. 2003; 71:1. [PubMed: 12749590] (b) Bishop-Bailey D. Br. J. Pharmacol. 2000; 129:823. [PubMed: 10696077] (c) Dussault I, Forman BM. Prostaglandins Other Lipid Mediat. 2000; 62:1. [PubMed: 10936411] (d) Hihi AK, Michalik L, Wahli W. Cell. Mol. Life Sci. 2002; 59:790. [PubMed: 12088279] (e) Na HK, Surh YJ. Biochem. Pharmacol. 2003; 66:1381. [PubMed: 14555212]

4. (a) Lima ES, Bonini MG, Augusto O, Barbeiro HV, Souza HP, Abdalla DSP. Free Radic. Biol. Med. 2005; 39:532. [PubMed: 16043024] (b) Schopfer FJ, Baker PRS, Giles G, Chumley P, Batthyany C, Crawford J, Patel RP, Hogg N, Branchaud BP, Lancaster JR Jr, Freeman BA. J. Biol. Chem. 2005; 280:19289. [PubMed: 15764811]

5. (a) Kerwin JF Jr, Lancaster JR Jr, Feldman PL. J. Med. Chem. 1995; 38:4343. [PubMed: 7473563] (b) Umans JG, Levi R. Annu. Rev. Physiol. 1995; 57:771. [PubMed: 7539996] (c) Wang PG, Xian M, Tang X, Wu X, Wen Z, Cai T, Janczuk AJ. Chem. Rev. 2002; 102:1091. and references therein. [PubMed: 11942788] (d) Thatcher GRJ. Curr. Top. Med. Chem. 2005; 5:597. [PubMed: 16101422]

6. Baker PRS, Lin Y, Schopfer FJ, Woodcock SR, Groeger AL, Batthyany C, Sweeney S, Long MH, Iles KE, Baker LMS, Branchaud BP, Chen YE, Freeman BA. J. Biol. Chem. 2005; 280:42464. [PubMed: 16227625]

7. Lim DG, Sweeney S, Bloodsworth A, White CR, Chumley PH, Krishna NR, Schopfer FJ, O'Donnell VB, Eiserich JP, Freeman BA. Proc. Natl. Acad. Sci. USA. 2002; 99:15941. [PubMed: 12444258]

8. (a) Hamaya T, Tomoda S, Takeuchi Y, Nomura Y. Tetrahedron Lett. 1982; 23:4733.(b) Seebach D, Calderari G, Knochel P. Tetrahedron. 1985; 41:4861.

9. (a) O'Donnell VB, Eiserich JP, Bloodsworth A, Chumley PH, Kirk M, Barnes S, Darley-Usmar VM, Freeman BA. Methods Enzymol. 1999; 301:454. [PubMed: 9919594] (b) Napolitano A, Camera E, Picardo M, d'Ischia M. J. Org. Chem. 2000; 65:4853. [PubMed: 10956463]

10. Li G-Y, Che C-M. Org. Lett. 2004; 6:1621. [PubMed: 15128251]

11. Denmark SE, Kesler BS, Moon Y-C. J. Org. Chem. 1992; 57:4912.

12. Wollenberg RH, Miller SJ. Tetrahedron Lett. 1978; 19:3219.

13. (a) Lucet D, Heyse P, Gissot A, Le Gall T, Mioskowski C. Eur. J. Org. Chem. 2000:3575.(b)

Denmark SE, Gomez L. J. Org. Chem. 2003; 68:8015. [PubMed: 14535778]

14. Gung BW, Dickson H. Org. Lett. 2002; 4:2517. [PubMed: 12123365] 


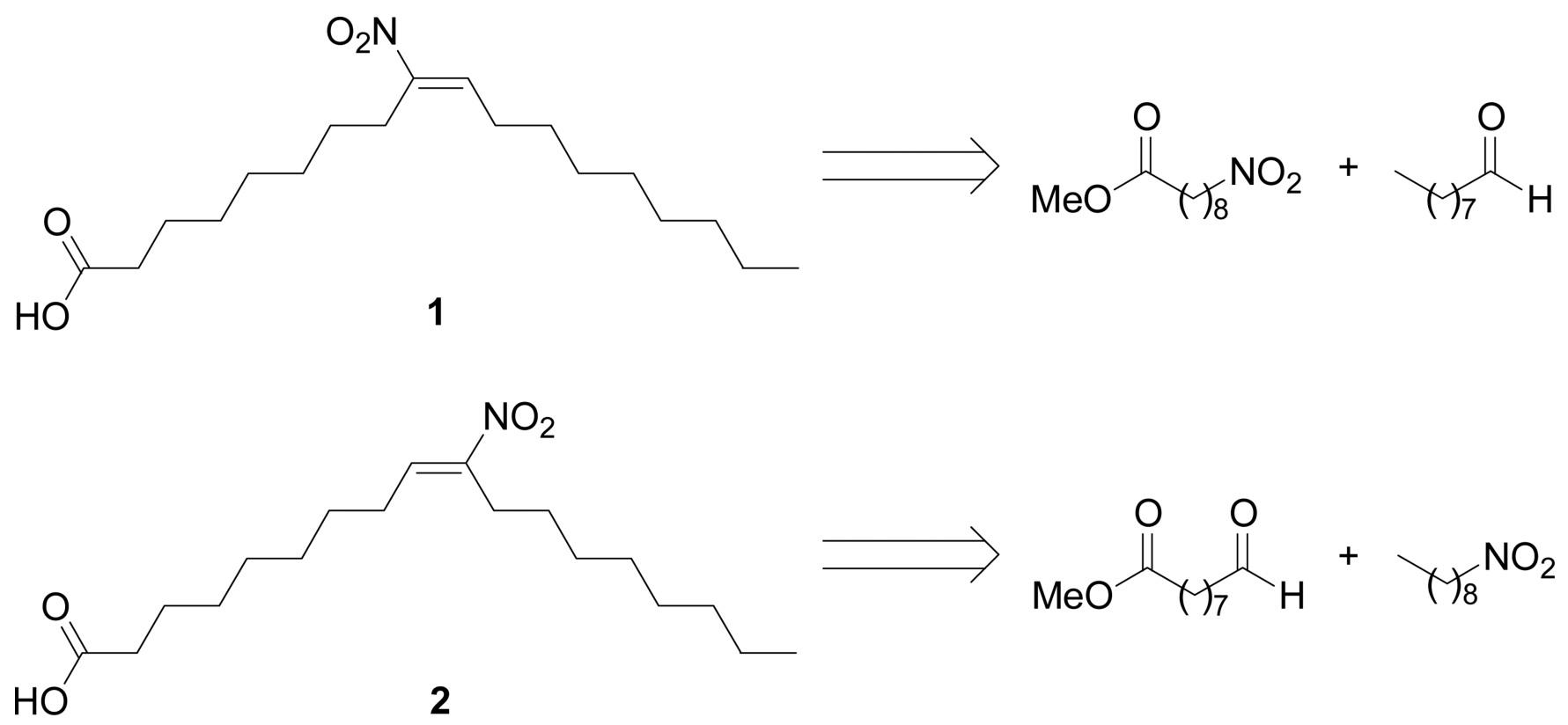

Scheme 1.

Retrosynthetic analysis for nitrooleic acid isomers, $\mathbf{1}$ and $\mathbf{2}$. 

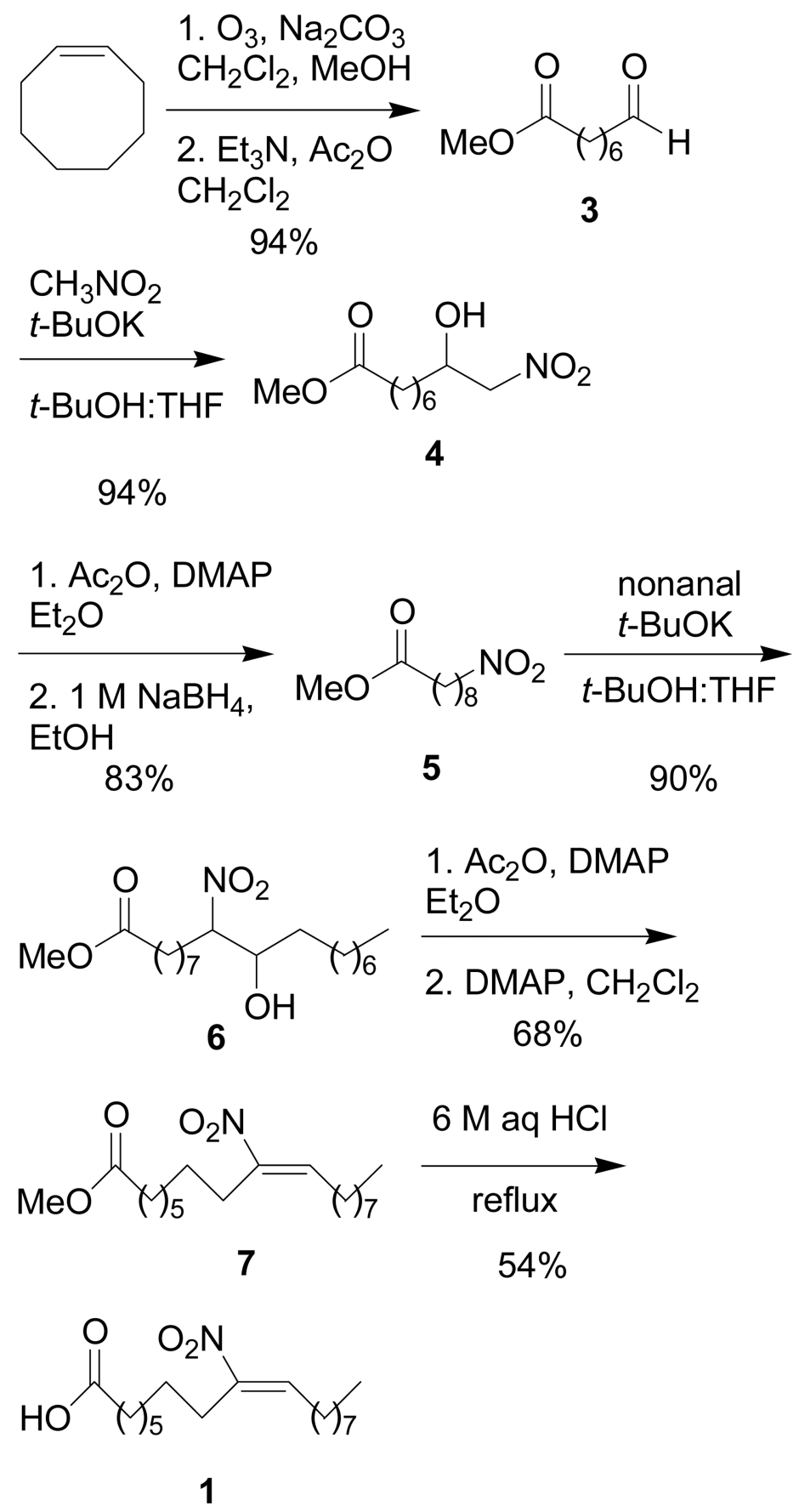

Scheme 2.

Synthesis of (E)-9-nitrooctadec-9-enoic acid, $\mathbf{1}$. 


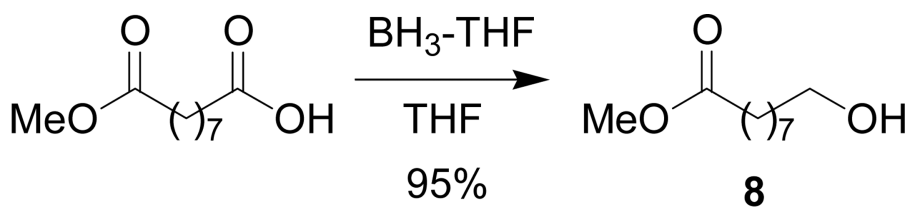

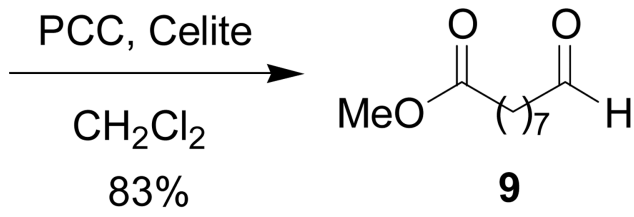

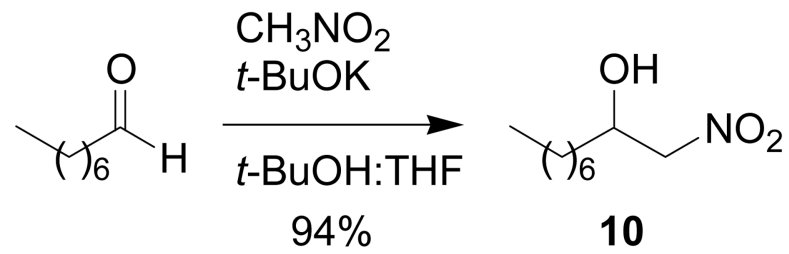

1. $\mathrm{Ac}_{2} \mathrm{O}, \mathrm{DMAP}$

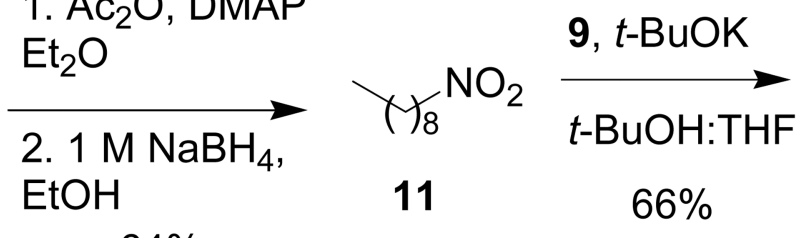<smiles>COC(=O)CCC(=O)OCC(=O)OC</smiles>

12 $42 \%$<smiles>[R]C(=CCCC(=O)OC)[N+](=O)[O-]</smiles><smiles>[Y10]C(=CCCCC([Y6])C(=O)O)[N+](=O)[O-]</smiles>

2

Scheme 3.

Synthesis of (E)-10-nitrooctadec-9-enoic acid, 2. 


\section{Table 1}

Chemiluminescence detection of Nitric oxide and nitrite release from 1, 2, 7, and 13 (50 mM).

\begin{tabular}{cccc}
\hline compound & $\begin{array}{c}\text { incubation time } \\
(\mathbf{h})\end{array}$ & $\begin{array}{c}{[\mathbf{N O}]_{\text {headspace }}} \\
(\boldsymbol{\mu M})^{\boldsymbol{a}, \boldsymbol{b}}\end{array}$ & $\begin{array}{c}\left.\mathbf{N O}_{2}^{-}\right]_{\text {solution }} \\
(\boldsymbol{\mu M})^{\boldsymbol{a}, \boldsymbol{c}}\end{array}$ \\
\hline $\mathbf{1}$ & 1 & $1.93 \pm 0.11$ & $\mathrm{ND}$ \\
& 3 & $1.76 \pm 0.13$ & $10.98 \pm 0.77$ \\
& 20 & $4.23 \pm 0.43$ & $25.71 \pm 0.58$ \\
$\mathbf{2}$ & 1 & $2.30 \pm 0.02$ & $\mathrm{ND}$ \\
& 3 & $3.20 \pm 0.14$ & $6.63 \pm 0.60$ \\
& 20 & $22.09 \pm 1.26$ & $23.79 \pm 1.27$ \\
$\mathbf{7}$ & 1 & $3.63 \pm 0.45^{d, e}$ & $53.98 \pm 4.28^{f}$ \\
$\mathbf{1 3}$ & 1 & $0^{e}$ & $1.85 \pm 0.10^{f}$ \\
\hline
\end{tabular}

${ }^{a}$ Dissolved in phosphate buffer (25 mM, pH 7.4).

$b_{500 \mu \mathrm{L} \text { injection. }}$

$c_{5 \mu \mathrm{L} \text { injection. }}$

${ }^{d}$ Dissolved in 1:1 EtOH: phosphate buffer (25 mM, pH 7.4).

$e_{100 \mu \mathrm{L} \text { injection. }}$

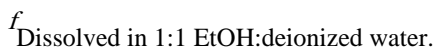

$\mathrm{ND}=$ no data 